\title{
Disaster Risk Reduction Knowledge among local people in a Selected Community in the Philippines
}

\author{
GIL P. SORIANO, MHPEd, RN \\ https://orcid.org/0000-0002-6349-5560 \\ San Beda University, Manila, Philippines \\ Corresponding author's email: gpsoriano@sanbeda.edu.ph
}

\section{Abstract}

Background: The Philippines has been classified as highly vulnerable to natural disasters. Hence, reinforcing the capacities of communities towards the risk and adverse impacts of natural hazards is essential in order to reduce vulnerability and managed disasters. The study assessed disaster-related knowledge including (1) disaster preparedness and readiness, (2) disaster adaptation, (3) disaster awareness, and (4) disaster risk perception of the local people in a selected community.

Methods: A descriptive-cross sectional study was utilized and a convenience sampling technique was used to select the 60 participants. The disaster risk reduction knowledge was assessed using the Disaster Risk Reduction Knowledge questionnaire. The gathered data were analyzed using frequency, percentage, mean, standard deviation and univariate linear regression.

Results: The study revealed that the local people in the selected community have good knowledge on disaster preparedness and readiness, disaster adaptation, and disaster awareness and fair knowledge on disaster-related knowledge and disaster risk perception. Further, age, sex, civil status, and education did not predict the level of disaster risk reduction knowledge.

Conclusion: The initiatives for disaster education in the Philippines are sufficient as evidenced by a good level of disaster risk reduction knowledge among the local people in the selected community.

Keywords: Disaster risk reduction knowledge, natural disaster, peacebuilding 


\section{Introduction}

eacebuilding as defined by Wyeth (2011) refers to strategies that promotes transformation of society by reducing the vulnerabilities, addressing the root causes of conflict, building the capacities of society, and developing institutions to manage conflict. One example is the occurrence of natural disasters which showed an incessant increase during the last decades (Harries, Keen \& Mitchell, 2013). The Global Climate Risk Index (2013), revealed that the most affected countries in 2011 were Thailand, Cambodia, Pakistan, El Salvador and the Philippines (Harmeling \& Eckstein, 2012). Thus, the index reconfirms that developing countries are more affected than developing ones not simply because of the geographical location but due to their vulnerability to risks. Vulnerability as defined by United Nations International Strategy for Disaster Reduction (UNISDR, 2009), refers to the characteristics and circumstances of a community, system or asset that make it susceptible to the damaging effects of a hazard.

The Philippines is known to be highly vulnerable to natural disasters ranking third out of 173 countries in terms of vulnerability to disaster risk (United Nations University- Institute for Environment and Human Security, 2011). Disaster risk is expressed in terms of potential loss of lives, deterioration of health status and livelihoods, and potential damage to assets and services due to impact of existing natural hazard. (Tuladhar, Yatabe, Dahal, \& Bhandary, 2015). Hence, the country placed special emphasis on minimizing disaster risk by developing strategies for Disaster Risk Reduction (DRR). DRR is a systematic approach to identify, assess and reduce disaster risk (Onstada et al., 2012) and avert the unfavorable effects of natural disasters, facilitating a sustainable development process. The Hyogo Framework for Action 2005-2015: Building the Resilience of Nations and Communities to Disasters (HFA) serves as the global blueprint for disaster risk reduction (DRR) efforts. Further, it plays an integral part in managing disasters by reinforcing the capacities of communities towards the risk and adverse impacts of natural hazards (Saño, 2010).

HFA states that all countries must use knowledge, innovation, and education to build a culture of safety and resilience at all levels (Tuladhar et al., 2015). Thus, as one of the countries who agreed in the implementation of HFA, the Philippines passed the Republic Act 10121 or the Philippine Disaster Risk Reduction Management Act also known as DRRM Act in order to show its commitment in promoting and implementing measures for DRR. One of the features of the DRRM Act focuses on an integrated, coordinated, multi-sectoral, inter-agency and community-based approach to disaster risk reduction (Saño, 2010), hence, the role of the local communities in disaster risk reduction cannot be undermined since they are most familiar with their situation. Further, when a disaster occurs, it is the people at the community level who suffer most of its adverse effect (Victoria, 2003). Hence, in order to substantially reduced disasters, people should be well informed and motivated about measures that they can take to reduce vulnerability and adverse effects. 
Thus, the study was conducted in order to assess the disaster-related knowledge, disaster preparedness and readiness, disaster adaptation, disaster awareness and disaster risk perception of the local people in selected community.

\section{Methods}

\section{Research design and Sampling Technique}

The study utilized a cross-sectional research as the study design to determine the disaster risk reduction knowledge of the participants in the select community. Further, convenience sampling was used to select the respondents of the study.

\section{Participants of the study}

In the study, a total population sampling was utilized however, only sixty (60) participants agreed to participate and answered the survey questionnaire. The participants included members of the selected community in Taytay, Rizal who were either male or female, aged 18 years old and above, those who have been living in the community for more than 12 months and those who agreed to participate in the study.

\section{Measurement and Instrumentation}

The study utilized a two-part questionnaire to measure the disaster risk reduction knowledge of the participants. The first part includes a personal information sheet which contains the participants' age, sex, civil status, and educational attainment, whereas the second part will contain the Disaster Risk Reduction Knowledge questionnaire developed by Tuladhar et al. (2015). This is a five-point Likert scale questionnaire consisting of 20 items divided into five subscales: disaster-related knowledge, disaster preparedness and readiness, disaster adaptation, disaster awareness and disaster risk perception. The said instrument was cross culturally adapted and translated following the World Health Organization guideline (WHO, n.d. as cited by Soriano \& Calong Calong, 2019). The Item-Content Validity Index (I-CVI) ranged from 0.88 to 1.0 while the ScaleContent Validity Index (S-CVI) of the tool was 0.92 which makes the translated tool content valid (Polit \& Beck, 2006 as cited by Soriano, 2019). For the internal consistency reliability, the over-all Cronbach's alpha coefficient of the tool was 0.892 whereas the subscales namely: disasterrelated knowledge, disaster preparedness and readiness, disaster adaptation, disaster awareness and disaster risk perception had a Cronbach's alpha of $0.70,0.748,0.758,0.718$ and 0.70 respectively which met the minimum criteria set by Polit and Beck (2014 as cited by Soriano \& Calong Calong, 2019). 


\section{Ethical Considerations}

The study conformed with the ethical standards of conducting research involving human participants. Also, the ethical clearance was secured from San Beda University-Research Ethics Board.

\section{Data Analysis}

The data gathered was analyzed using frequency, percentage, mean and standard deviation. Univariate linear regression was also used to determine the effect of demographic characteristics with the disaster-risk reduction knowledge among the participants.

\section{Result}

Table 1 shows the demographic profile of the participants. Based on the results, the mean age of the participants was $33.4( \pm 13.27)$, while majority of them were females $(65 \%)$, married $(50 \%)$ and was able to finish high school education (53.35\%).

Table 1. Demographic Profile of the Participants $(n=60)$

\begin{tabular}{lccc}
\hline \multicolumn{1}{c}{ Characteristics } & Frequency (f) & Percentage (\%) & Mean (SD) \\
\hline Age (Years) & & & $33.4( \pm 13.27)$ \\
Sex & & $35 \%$ & \\
$\quad$ Male & 21 & $65 \%$ & \\
$\quad$ Female & 39 & & \\
Civil Status & & $43.3 \%$ & \\
$\quad$ Single & 26 & $56.7 \%$ & \\
$\quad$ Married & 34 & & \\
Education & & $41.7 \%$ & \\
$\quad$ Elementary Graduate & 25 & $58.3 \%$ & \\
$\quad$ High School Graduate & 35 & & \\
\hline
\end{tabular}

As shown in Table 2, the mean disaster-risk reduction knowledge of the participants is 3.64 $( \pm 0.74)$ which can be interpreted as good. The mean disaster preparedness and readiness, disaster adaptation and disaster awareness knowledge fall between 3.63 and 4.16 which denotes a good level of knowledge. On the other hand, the mean disaster-related knowledge and mean disaster risk perception knowledge was 3.31 and 3.07 which can be interpreted as fair knowledge. 
Table 2. Descriptive Statistics of Disaster-Risk Reduction Knowledge $(n=60)$

\begin{tabular}{|c|c|c|c|c|}
\hline & & Mean & $\begin{array}{l}\text { Standard } \\
\text { Deviation }\end{array}$ & Interpretation \\
\hline \multicolumn{2}{|c|}{ Disaster-Risk Reduction Knowledge } & 3.64 & \pm 0.74 & Good \\
\hline \multicolumn{2}{|c|}{ Disaster-related knowledge } & 3.31 & \pm 1.15 & Fair \\
\hline \multicolumn{2}{|c|}{ Disaster preparedness and readiness } & 4.16 & \pm 0.78 & Good \\
\hline \multicolumn{2}{|c|}{ Disaster adaptation } & 3.63 & \pm 0.93 & Good \\
\hline \multicolumn{2}{|c|}{ Disaster awareness } & 3.64 & \pm 0.93 & Good \\
\hline \multicolumn{2}{|c|}{ Disaster risk perception } & 3.07 & \pm 1.09 & Fair \\
\hline \multirow[t]{3}{*}{ aLegend: } & No Knowledge $=1.00$ to 1.79 & \multicolumn{3}{|c|}{ Poor Knowledge= 1.80 to 2.59} \\
\hline & Fair Knowledge= 2.60 to 3.39 & \multicolumn{3}{|c|}{ Good Knowledge $=3.40$ to 4.19} \\
\hline & \multicolumn{4}{|c|}{ Excellent Knowledge $=4.20$ to 5.00} \\
\hline
\end{tabular}

Table 3 shows the influence of the demographic profile with disaster-risk reduction knowledge. It was revealed that the identified demographic profiles did significantly predict the disaster-risk reduction knowledge of the local people in the selected community.

Table 3. Univariate linear regression of Disaster-Risk Reduction Knowledge $(n=60)$

\begin{tabular}{|c|c|c|c|c|c|c|c|c|}
\hline & & Source & B & SE B & $\beta$ & $t$ & $p$ & $\begin{array}{c}\mathbf{R} \\
\text { squared }\end{array}$ \\
\hline \multirow{4}{*}{\multicolumn{2}{|c|}{$\begin{array}{l}\text { Disaster-risk } \\
\text { knowledge }\end{array}$}} & Age & 0.012 & 0.008 & 0.208 & 1.616 & 0.112 & 0.043 \\
\hline & & Sex & -0.125 & 0.212 & -0.077 & -0.586 & 0.560 & 0.006 \\
\hline & & $\begin{array}{l}\text { Civil } \\
\text { Status }\end{array}$ & 0.179 & 0.166 & 0.140 & 1.078 & 0.286 & 0.020 \\
\hline & & Education & -0.154 & 0.175 & -0.115 & -0.878 & 0.383 & 0.013 \\
\hline
\end{tabular}

\section{Discussion}

The study aimed to determine the disaster risk reduction knowledge among the local people in the selected community in terms of disaster related knowledge, disaster preparedness and readiness, disaster adaptation and disaster risk perception. The findings revealed that local people in the selected community have a good knowledge in terms of disaster awareness. The result may be related to the experiences of Filipinos in several disasters that struck the country includes the Bohol earthquake and Typhoon Haiyan in 2013. Further, the Philippine government has made important changes in terms of managing disasters. According to UNISDR (2009), the Philippines collected comprehensive and updated risk information with the use of modern technologies and techniques.

Another possible reason is the involvement of the community in disaster preparedness and mitigation programs. Zubir \& Amirrol (2011) highlighted that communities must be aware of the 
importance of disaster reduction for their own well-being. Measures to develop essential skills that can translate risk awareness into concrete practices of sustained risk management becomes a necessity. Further, several studies have revealed that the approach to disaster mitigation is becoming more and more community-based (Begg, Haines \& Hurlbert, 1996; Blaikie, Cannon, Davis, \& Wisner, 1994; Twigg, 1999; Quarantellu, 1989; Mileti, 2001) and considerable amount of work effort has been done in order to incorporate aspects of disaster management into the holistic development of communities.

Community involvement in disaster preparedness and mitigation has also been shown to become an effective measure of reducing vulnerabilities (Victoria, 2003; Abinales, 2002; Hejimans \& Victoria, 2001). It can be shown in the results that the local people in the selected community has a good level of knowledge in terms of disaster preparedness and readiness. However, according to Victoria (2003), local communities cannot reduce vulnerabilities on their own and a strong mitigation measures and collaborative action among multiple-stakeholders from various disciplines and levels of the disaster management and development planning system are necessary.

In 2010, the Philippines promulgated the Republic Act 10121 or the Philippine Disaster Risk Reduction Management Act, which strengthens the management of disaster risk through disaster risk governance. Under this law, the Philippine Disaster Risk Reduction Management Act has been created with the National Disaster Risk Reduction and Management Council (NDRRMC), as the highest decision-making body. It comprises of members from different departments, government agencies, LGUs, Civil Society Organizations and private sector. A vertical coordination consisting of multi-tiered bodies comprising of Disaster Risk Reduction and Management Office (DRRMO) in every province, city, municipality and down to the Barangay or community level with the Barangay Disaster Risk Reduction and Management Committee (BDRRMC).

Overall, the disaster risk reduction knowledge of the local people in the selected community was rated as good. This can be attributed to the continuous information dissemination campaign made by the government in partnership with school, universities and communities such as the conduct of earthquake and fire drill. Further, the DRRM is also integrated in the basic education framework and college curriculum.

Despite positive results, the major limitation of the study is the number of samples which limits its generalizability. However, the major contribution of this research is the significant measures taken by the government in order to integrate disaster preparedness and mitigation not only in the school curriculum but also in the community level. 


\section{Conclusion}

The initiatives for disaster education in the Philippines are sufficient as evidenced by good level of disaster risk reduction knowledge among the local people in the selected community.

\section{Funding}

This research is funded by San Beda University through its Research and Development Center, AY 2019-2020 Research Grants.

\section{References}

Abinales, N. (2002). In Times of Affliction: God and Preparedness are our Protection. Retrieved from: http://karchive.pssc.org.ph/bitstream/handle/0/4187/13_In\%20Times\%20of\%20Affliction_\%20God\%20and \%20Preparedness\%20are\%20our\%20Protection.pdf?sequence=1

Beggs, J., Haines, V., \& Hurlbert, J. (1996). Situational Contingencies Surrounding the Receipt of Informal Support. Social Forces, 75 (1), 201-222.

Blaikie, P., Cannon, T., Davis, I., \& Wisner, B. (1994). At Risk: natural hazards, people's vulnerability, and disaster. London, UK: Routledge.

Harmeling, S. \& Eckstein, D. (2012). Global Climate Risk Index 2013: Who Suffers Most from Extreme Weather Events? Weather-Related Loss Events in 2011 and 1992 to 2011. Retrieved from: https://germanwatch.org/sites/germanwatch.org/files/publication/7170.pdf

Heijmans, A. \& Victoria, L. (2001). CBDO-DR: Experiences and Practices in Disaster Management of the Citizens' Disaster Response Network in the Philippines. Quezon City

Harris, K., Keen, D., Mitchell, T. (2013). When disasters and conflicts collide: Improving links between disaster resilience and conflict prevention. Retrieved from: https://www.odi.org/sites/odi.org.uk/files/odiassets/publications-opinion-files/8228.pdf

Lynn, M.R. (1986). Determination and quantification of content validity. Nursing Research, 35, 382-385

Mileti, D. S. (2001). Disasters by Design. Washington D.C: Joseph Henry Press.

Onstada, P. A., Danesb, S. M., Hardmanc, A. M., Olsonc, P. D., Marczakc, M. S. \& Heinsd, R. K. (2012). The road to recovery from a natural disaster: voices from the community. Community Development. 43(5), 566-580.

Quarantelli E. L. (1989). Conceptualizing Disasters from a Sociological Perspective. International Journal of Mass Emergencies and Disasters. 7, 243-251.

Saño, E.A. (2010). Primer on the Disaster Risk Reduction and Management (DRRM) Act of 2010. Retrieved from: http://downloads.caraga.dilg.gov.ph/Disaster\%20Preparedness/DRRM\%20Act20Primer.pdf.

Soriano, G.P. \& Calong Calong, K.A. (2019). Psychometric Evaluation of Filipino Version of Patient Satisfaction Instrument. Belitung Nursing Journal, 5 (6), 251-256. doi: 10.33546/bnj.867

Soriano, G. \& Calong Calong, K. (2019). Construct Validity and Reliability of Caring Nurse Patient Interaction Scale-Nurse among Filipino Nurses. International Journal of Caring Sciences, 12(2), 1017-1022 
Soriano, G. (2019). Psychometric Evaluation of the Filipino Version of Caring Nurse Patient Interaction ScalePatient. International Journal for Human Caring, 23(4), 329-333. doi:10.20467/1091-5710.23.4.329

Tuladhar, G., Yatabe, R., Dahal, R., Bhandary, N. (2015). Disaster risk reduction knowledge of local people in Nepal. Geoenvironmental Disasters, 2:5. doi: 10.1186/s40677-014-0011-4

Twigg, J. (1999). The Age of Accountability? Future Community Involvement, in: Disaster Reduction. Australian Journal of Emergency Management, 14(4), 51-58

United Nations University - Institute for Environment and Human Security (2011). World Risk Report 2011. Retrieved from https://collections.unu.edu/eserv/UNU:2046/WorldRiskReport-2011_online_EN.pdf

UNISDR (2009). UNISDR Terminology on Disaster Risk Reduction, United Nations International Strategy for Disaster Reduction (UNISDR), Geneva.

Victoria, L. (2003). Community-based disaster management in the Philippines: making a difference in people's lives. Philippine Sociological Review. 51, 65-80.

Wyeth, Vanessa (2011). Peacebuilding at the UN over the last 10 years, Working Group on Peace and Development (FriEnt), Bonn.

Zubir, S. \& Amirrol, H. (2011). Disaster risk reduction through community participation. WIT Transactions on Ecology and The Environment. 148, 195-206. doi: 10.2495/RAV110191

\section{About the Author}

Gil P. Soriano, MHPEd, RN earned his Bachelor of Science in Nursing degree from Pamantasan ng Lungsod ng Pasay and his Master of Health Profe ssions Education from the University of the Philippines Manila under a UP Presidential Scholarship Grant. Currently, he is the Level 3 Coordinator and Community Coordinator of San Beda University-College of Nursing. He has presented researches in various national and international research fora and has published a number of research articles in reputable/indexed journals focusing on Public Health, Caring Science, and Nursing Pedagogy. 